\title{
Prognostic Value of Body Mass Index on Short-Term and Long-Term Outcome after Resection of Esophageal Cancer
}

\author{
B. A. Grotenhuis • B. P. L. Wijnhoven • \\ G. J. Hötte - E. P. van der Stok • H. W. Tilanus • \\ J. J. B. van Lanschot
}

Published online: 2 July 2010

(c) The Author(s) 2010. This article is published with open access at Springerlink.com

\begin{abstract}
Introduction Cachexia and obesity have been suggested to be risk factors for postoperative complications. However, high body mass index (BMI) might result in a higher $\mathrm{R} 0$-resection rate because of the presence of more fatty tissue surrounding the tumor. The purpose of this study was to investigate whether BMI is of prognostic value with regard to short-term and long-term outcome in patients who undergo esophagectomy for cancer.

Methods In 556 patients who underwent esophagectomy (1991-2007), clinical and pathological outcome were compared between different BMI classes (underweight, normal weight, overweight, obesity).

Results Overall morbidity, mortality, and reoperation rate did not differ in underweight and obese patients. However, severe complications seemed to occur more often in obese patients $(p=0.06)$, and the risk for anastomotic leakage increased with higher BMI (12.5\% in underweight patients compared with $27.6 \%$ in obese patients, $p=0.04$ ). Histopathological assessment showed comparable pTNM stages, although an advanced pT stage was seen more often in patients with low/normal BMI $(p=0.02)$. A linear association between BMI and R0-resection rate was detected $(p=0.02): 60 \%$ in underweight patients compared with $81 \%$ in obese patients. However, unlike pT-stage $(p<0.001)$, BMI was not an independent predictor for R0 resection $(p=0.12)$. There was no significant difference in
\end{abstract}

B. A. Grotenhuis $(\bowtie)$ • B. P. L. Wijnhoven ·

G. J. Hötte - E. P. van der Stok · H. W. Tilanus

J. J. B. van Lanschot

Department of Surgery, Erasmus Medical Center,

Erasmus University, P.O. Box 2040, 3000 CA Rotterdam,

The Netherlands

e-mail: b.grotenhuis@erasmusmc.nl overall or disease-free 5-year survival between the BMI classes ( $p=0.25$ and $p=0.6$, respectively).

Conclusions BMI is not of prognostic value with regard to short-term and long-term outcome in patients who undergo esophagectomy for cancer and is not an independent predictor for radical R0 resection. Patients oncologically eligible for esophagectomy should not be denied surgery on the basis of their BMI class.

\section{Introduction}

Among patients with esophageal cancer weight loss is common, which is caused by malnutrition due to reduced food intake (mostly related to dysphagia) and increased demands because of systemic inflammation (cancer cachexia) [1]. Malnutrition has long been recognized as a condition associated with an increased risk of postoperative complications [2], in particular infectious complications [3]. It is unclear which mechanism is responsible for the relationship between malnutrition and an adverse short-term clinical outcome, but a combination of immune, inflammatory, and metabolic processes is thought to play a role [3].

The prevalence of obesity (defined as body mass index $(\mathrm{BMI})>30.00)$ among adults has increased over the past decades in the Western world [4,5]. Obesity is associated with several medical comorbidities, including diabetes, hypertension, and coronary artery disease [6]. In addition, increased $\mathrm{BMI}$ is associated with a higher risk of several types of cancers [7], including esophageal adenocarcinoma [8]. Surgery and anesthesia are more hazardous in overweight patients, not least because of the increased incidence of cardiorespiratory comorbidity [9]. Obese patients are at a higher risk for developing respiratory complications, because their pulmonary function is characterized by reductions in functional 
residual capacity and expiratory reserve volume [9-11]. The presence of excessive subcutaneous fat also may predispose obese patients to impaired wound healing and wound infections [12]. On the other hand, it might be hypothesized that in patients with a high BMI (and increased visceral fatty tissue), a higher percentage of tumor-free circumferential resection margins might be achieved because of the presence of more fatty tissue surrounding the tumor compared with patients with a low BMI when performing esophagectomy for cancer.

To improve outcome after esophagectomy, an optimal treatment strategy should be based on appropriate patient selection, which is strongly influenced by preoperative risk assessment. However, preoperative nutritional condition has received minor attention in risk analyses for esophagectomy thus far. The purpose of the present study was to investigate whether BMI is of prognostic value with regard to postoperative short-term and long-term outcomes in patients who undergo esophagectomy for cancer. We hypothesized on the one hand that patients with underweight or obesity are at higher risk for perioperative morbidity and mortality after esophagectomy, and that on the other hand increased BMI with excessive peritumoral fatty tissue might facilitate a radical (R0-) resection.

\section{Patients and methods}

\section{Patients}

Between January 1991 and December 2007, 791 patients underwent an esophagectomy for cancer of the esophagus or gastroesophageal junction in the Erasmus Medical Center in Rotterdam, The Netherlands. Only patients in whom no chemo- and/or radiotherapy was applied and who underwent a transthoracic or transhiatal esophagectomy were included in the present study. In the Erasmus MC, patients received neoadjuvant chemo(radio)therapy in the context of clinical trials [13]. Induction chemo- and/or radiotherapy was given to patients with a cT4-tumor without distant metastases or to patients with gross involvement of celiac trunk lymph nodes (M1a), who were not considered eligible for primary surgical therapy. There were 214 patients who were excluded because of chemo- and/or radiotherapy before surgery and 21 patients because of unknown preoperative BMI. The remaining 556 patients were included in this study.

\section{Surgery}

The majority of patients underwent a transhiatal esophagectomy $(\mathrm{N}=541)$. The primary tumor and its adjacent lymph nodes were dissected under direct vision through the widened hiatus of the diaphragm up to the level of the inferior pulmonary vein. In addition, all adjacent fatty tissue surrounding the tumor was removed simultaneously, until the lateral resection margins were reached (diaphragm, pleura, pericardium, aorta). Subsequently, a gastric tube was created. The left gastric artery was transected at its origin, with resection of celiac trunk lymph nodes. After mobilization and transection of the cervical esophagus, the normal intrathoracic esophagus proximal to the primary tumor was mobilized bluntly from the neck to the abdomen with a vein stripper. Esophagogastrostomy (handsewn or by using a circular stapler) was performed in the neck. Posterolateral thoracotomy was the first step in transthoracic resection with extended lymphadenectomy $(\mathrm{N}=15)$. The thoracic duct, azygos vein, ipsilateral pleura, and all periesophageal tissue in the posterior mediastinum were dissected en bloc. The resection specimen included the lower and middle mediastinal, subcarinal, and right-sided paratracheal lymph nodes. The aorta-pulmonary-window nodes were dissected separately. Through a midline laparotomy, the paracardial, lesser curvature, left-gastric-artery, celiac trunk, common-hepatic-artery, and splenic-artery nodes were dissected, and a gastric tube was constructed. The cervical phase of the transthoracic procedure was identical to that of the transhiatal procedure. Tumors were assigned pathologic tumor-node-metastasis stages according to the Union Internationale Contre le Cancer (UICC) 2002 system [14].

\section{Data collection}

Patients' weight and length were measured at their first visit to the outpatient clinic. Patients' BMI was calculated and classified according to the World Health Organization criteria (underweight: BMI $<18.50 \mathrm{~kg} / \mathrm{m}^{2}$; normal weight: BMI 18.50-24.99 kg/m²; overweight: BMI 25.00-29.99 $\mathrm{kg} / \mathrm{m}^{2}$; obesity: BMI $\geq 30.00 \mathrm{~kg} / \mathrm{m}^{2}$ ) [15]. Outcome data (including half-yearly follow-up) for all patients with esophageal cancer referred to our hospital for further analysis and treatment had been collected prospectively and stored in a database by a specialized data manager. Follow-up was recorded until December 2008 or until death if earlier and was complete for all patients.

\section{Statistics}

To address the question of whether patients with underweight or obesity are at higher risk for perioperative morbidity and mortality after esophagectomy, short-term outcome of underweight and obese patients was compared with outcome of the control group (patients with normal weight or overweight). The potential impact of BMI on histopathological outcome was considered to be on a linear scale (i.e., increased BMI might result in a higher percentage $\mathrm{R} 0$ resections) and was analyzed by comparing patients' outcome of the four BMI classes.

Statistical analysis appropriate for nonparametric data was used. Grouped data as presented in Tables 1 and 2 
Table 1 Impact of underweight and obesity on postoperative complications and in-hospital mortality in patients undergoing esophagectomy for cancer compared with the control group (normal weight and overweight patients)

$B M I$ body mass index

* Respiratory insufficiency was defined as pulmonary dysfunction requiring prolonged ventilation ( $>10$ days) or reintubation

Table 2 Histopathological assessment of the resection specimens in relation to four BMI classes in 556 patients who underwent surgical resection for esophageal cancer

$B M I$ body mass index,

$S C C$ squamous cell carcinoma,

$A C$ adenocarcinoma, lymph node ratio number of positive lymph nodes/total number of harvested lymph nodes

* Values presented as median (range in brackets)

\begin{tabular}{lcccc}
\hline & $\begin{array}{l}\text { Underweight } \\
\text { BMI }<18.50 \\
(N=40)\end{array}$ & $\begin{array}{l}\text { Control group } \\
\text { BMI 18.50-29.99 } \\
(N=458)\end{array}$ & $\begin{array}{l}\text { Obesity } \\
\text { BMI } \geq 30.00 \\
(N=58)\end{array}$ & $p$ value \\
\hline $\begin{array}{l}\text { Postoperative complications } \\
\text { Surgical complications }\end{array}$ & $20(50 \%)$ & $294(64.2 \%)$ & $34(58.6 \%)$ & 0.17 \\
Bleeding & $1(2.5 \%)$ & $13(2.8 \%)$ & $0(0 \%)$ & 0.43 \\
Chyle leakage & $1(2.5 \%)$ & $12(12.6 \%)$ & $1(1.7 \%)$ & 0.92 \\
Anastomotic leakage & $5(12.5 \%)$ & $77(16.8 \%)$ & $16(27.6 \%)$ & 0.09 \\
Conduit necrosis & $0(0.0 \%)$ & $11(2.4 \%)$ & $1(1.7 \%)$ & 0.59 \\
Vocal cord paresis & $4(10.0 \%)$ & $67(14.6 \%)$ & $4(6.9 \%)$ & 0.16 \\
Wound infection & $1(2.5 \%)$ & $43(9.4 \%)$ & $7(12.1 \%)$ & 0.25 \\
Medical complications & $1(2.5 \%)$ & $29(6.3 \%)$ & $3(5.2 \%)$ & 0.6 \\
Sepsis & $11(27.5 \%)$ & $149(32.5 \%)$ & $12(20.7 \%)$ & 0.16 \\
Pneumonia & $5(12.5 \%)$ & $40(8.7 \%)$ & $6(10.3 \%)$ & 0.69 \\
Respiratory insufficiency* & $3(7.5 \%)$ & $39(8.5 \%)$ & $3(5.2 \%)$ & 0.67 \\
Atrial fibrillation & $0(0 \%)$ & $5(1.1 \%)$ & $2(3.4 \%)$ & 0.24 \\
Myocardial infarction & $0(0 \%)$ & $10(2.2 \%)$ & $2(3.4 \%)$ & 0.51 \\
Thromboembolism & $3(7.5 \%)$ & $54(11.8 \%)$ & $5(8.6 \%)$ & 0.58 \\
Reoperation & $1(2.5 \%)$ & $27(5.9 \%)$ & $5(8.6 \%)$ & 0.45 \\
In-hospital mortality & & & &
\end{tabular}

\begin{tabular}{|c|c|c|c|c|c|}
\hline & $\begin{array}{l}\text { Underweight } \\
\mathrm{BMI}<18.50 \\
\mathrm{~N}=40\end{array}$ & $\begin{array}{l}\text { Normal weight } \\
\text { BMI 18.50-24.99 } \\
\mathrm{N}=244\end{array}$ & $\begin{array}{l}\text { Overweight } \\
\text { BMI 25.00-29.99 } \\
\mathrm{N}=214\end{array}$ & $\begin{array}{l}\text { Obesity } \\
\mathrm{BMI} \geq 30.00 \\
\mathrm{~N}=58\end{array}$ & $p$-value \\
\hline \multicolumn{6}{|l|}{ Histology } \\
\hline SCC & $22(55.0 \%)$ & $29(11.9 \%)$ & $26(12.1 \%)$ & $6(10.3 \%)$ & \\
\hline $\mathrm{AC}$ & $18(45.0 \%)$ & $215(88.1 \%)$ & $188(87.9 \%)$ & $52(89.7 \%)$ & $<0.001$ \\
\hline \multicolumn{6}{|l|}{ pT-status } \\
\hline $\mathrm{T} 1-\mathrm{T} 2$ & $10(25.0 \%)$ & $65(26.6 \%)$ & $83(38.8 \%)$ & $23(39.7 \%)$ & \\
\hline $\mathrm{T} 3-\mathrm{T} 4$ & $30(75.0 \%)$ & $179(73.4 \%)$ & $131(61.2 \%)$ & $35(60.3 \%)$ & 0.02 \\
\hline \multicolumn{6}{|l|}{ pN-status } \\
\hline No & $16(40.0 \%)$ & $84(34.4 \%)$ & $81(37.9 \%)$ & $24(41.4 \%)$ & \\
\hline N1 & $24(60.0 \%)$ & $160(65.6 \%)$ & $133(62.2 \%)$ & $34(58.6 \%)$ & 0.94 \\
\hline \multicolumn{6}{|l|}{ pM-status } \\
\hline M0 & $32(80.0 \%)$ & $194(79.5 \%)$ & $164(76.6 \%)$ & $47(81.0 \%)$ & \\
\hline M1a-M1b & $8(20.0 \%)$ & $50(20.5 \%)$ & $50(23.4 \%)$ & $11(19.0 \%)$ & 0.84 \\
\hline \multicolumn{6}{|l|}{ Differentiation grade } \\
\hline G1 (good) & $4(10.0 \%)$ & $14(5.7 \%)$ & $17(7.9 \%)$ & $4(6.9 \%)$ & \\
\hline G2 (moderate) & $26(65.0 \%)$ & $111(45.5 \%)$ & $95(44.4 \%)$ & $22(37.9 \%)$ & \\
\hline G3 (poor) & $10(25.0 \%)$ & $119(48.8 \%)$ & $102(47.7 \%)$ & $32(55.2 \%)$ & 0.17 \\
\hline \multicolumn{6}{|l|}{ Type of resection } \\
\hline R0 & $24(60.0 \%)$ & $167(68.4 \%)$ & $154(72.0 \%)$ & $47(81.0 \%)$ & \\
\hline $\mathrm{R} 1-\mathrm{R} 2$ & $16(40.0 \%)$ & $77(31.6 \%)$ & $60(28.0 \%)$ & $11(19.0 \%)$ & 0.06 \\
\hline $\begin{array}{l}\text { Number of positive } \\
\text { lymph nodes* }\end{array}$ & $1(1-19)$ & $2(0-23)$ & $2(0-43)$ & $1(0-11)$ & 0.14 \\
\hline $\begin{array}{l}\text { Total number } \\
\text { of harvested } \\
\text { lymph nodes* }\end{array}$ & $10(3-45)$ & $12(1-56)$ & $10(1-43)$ & $9(2-31)$ & 0.10 \\
\hline $\begin{array}{l}\text { Lymph node } \\
\text { ratio* }\end{array}$ & 0.10 & 0.17 & 0.16 & 0.10 & 0.14 \\
\hline
\end{tabular}


were compared using the Chi-squared, Mann-Whitney $U$, or Kruskal-Wallis $\mathrm{H}$ test. In case these tests were significant (thereby indicating that there were differences but not indicating where the differences are), groups were compared pair-wise with adding the Bonferroni correction. Trend-analysis and logistic regression were performed to reveal linear associations with regard to BMI.

Overall survival was calculated from the date of operation until the date of last follow-up or death according to the Kaplan-Meier method. Patients who died due to complications after esophagectomy (in-hospital mortality) were not excluded from survival analysis. Univariate analyses were performed to identify prognostic variables associated with overall survival after esophagectomy.

Data analysis was performed with SPSS version 15.0 (SPSS, Inc., Chicago, IL, USA). Two-sided $p$ values $<0.05$ were considered to be significant.

\section{Results}

\section{Patients' characteristics}

Patients' characteristics are described in Table 3. Forty patients (7.2\%) were classified as underweight (BMI $<18.50 \mathrm{~kg} / \mathrm{m}^{2}$ ), 244 patients $(43.9 \%)$ had a normal weight (BMI 18.50$\left.24.99 \mathrm{~kg} / \mathrm{m}^{2}\right), 214$ patients $(38.5 \%)$ were overweight (BMI $\left.25.00-29.99 \mathrm{~kg} / \mathrm{m}^{2}\right)$, whereas obesity $(\mathrm{BMI}>30.00)$ was diagnosed in 58 patients (10.4\%).

\section{Short-term outcome}

Median operative time for all patients was 280 (range, 120-572) min. Operative time increased among the different BMI classes: median operative time was $266 \mathrm{~min}$ in underweight patients, $274 \mathrm{~min}$ in normal weight, $285 \mathrm{~min}$ in overweight, and $307 \mathrm{~min}$ in obese patients $(p=0.04)$. There was no significant difference in length of ICU-MCU (median, 4 days) or hospital stay (median, 14 days) between the different groups. When analyzing the effect of underweight or obesity on patients' short-term outcome, overall morbidity, reoperation rate, and in-hospital mortality were similar to those of the patients in the control group (normal weight or overweight; Table 1). However, when the grade of complications was taken into account, severe complications seemed to occur more often in obese patients than in the control group (36.4 vs. 21.8\%, $p=0.06)$. Furthermore, the incidence of anastomotic leakage (radiological as well as clinical) did not seem comparable between the three groups $(p=0.09)$. On trend analysis, a linear association between BMI and anastomotic leakage was detected $(p=0.04)$ : the risk for anastomotic leakage increased with higher BMI (from $12.5 \%$ in
Table 3 Clinicopathological characteristics of 556 patients who underwent surgical resection for esophageal cancer

\begin{tabular}{lc}
\hline Age (year)* & 65 (range 28-89) \\
\hline Gender & \\
Male & $450(80.9 \%)$ \\
Female & $106(19.1 \%)$ \\
ASA classification & \\
I & $82(14.7 \%)$ \\
II & $364(65.5 \%)$ \\
III & $106(19.1 \%)$ \\
IV & $4(0.7 \%)$ \\
BMI class & \\
Underweight (BMI < 18.50) & $40(7.2 \%)$ \\
Normal weight (BMI 18.50-24.99) & $244(43.9 \%)$ \\
Overweight (BMI 25.00-29.99) & $214(38.5 \%)$ \\
Obesity (BMI $\geq 30.00)$ & $58(10.4 \%)$ \\
Tumor location & \\
Proximal esophagus & $9(1.6 \%)$ \\
Mid esophagus & $32(5.8 \%)$ \\
Distal esophagus & $232(41.7 \%)$ \\
Gastroesophageal junction & $283(50.9 \%)$ \\
Histology & $83(14.9 \%)$ \\
Squamous cell carcinoma & $473(85.1 \%)$ \\
Adenocarcinoma &
\end{tabular}

ASA classification American society of anesthesiologists classification, $B M I$ body mass index

* Age is given as median

underweight patients to $27.6 \%$ in obese patients). Also, a trend for a linear association between BMI and wound infection was seen $(p=0.07)$ : from $2.5 \%$ in underweight patients to $12.1 \%$ in obese patients.

Histopathological assessment for the four different BMI classes is shown in Table 2. Advanced pT stage was seen significantly more often in patients with a low or normal BMI $(p<0.01)$. Patients with overweight or obesity appeared to participate more often in a surveillance program than patients with a low or normal BMI (28.8 vs. $17.1 \%, p=0.21)$. Underweight patients mostly suffered from squamous cell carcinoma (55\%), whereas the majority of patients with normal weight, overweight, or obesity was diagnosed with adenocarcinoma (89\%; $p<0.001)$. A trend toward a higher rate of radical resection (R0) across the BMI classes was noted $(p=0.06)$. On trend analysis, a linear association between BMI and R0-resection rate was detected $(p=0.02): 60 \%$ in underweight patients versus $81 \%$ in obese patients. However, unlike pT stage $(p<0.001)$, BMI was not an independent predictor for R0resection on logistic regression $(p=0.12)$. Stratification for tumor location (esophagus vs. gastroesophageal junction) did not influence the R0-resection rate. 
Long-term outcome

Median survival time was 20 (range, 0-193) months. Overall 5-year survival was $27.9 \%$, whereas disease-specific 5-year survival was $33.4 \%$. Disease recurrence was noted in 315 patients $(56.7 \%)$ : locoregional recurrence in $27.2 \%$ and distant metastases in $47.1 \%$ of patients. There was no significant difference in overall 5-year survival between the different BMI classes (Fig. 1: underweight $26.8 \%$, normal weight $25.2 \%$, overweight $28.5 \%$, and obesity $34.4 \% ; p=0.25$ ) or disease-free 5-year survival (28.8, 32.5, 33.2, and 35.1\%, respectively; $p=0.6)$. Parameters found to be associated with overall survival in univariate analyses are shown in Table 4. Age younger than 65 years, early pT stage (pT1 or pT2), no lymph node involvement ( $\mathrm{pN} 0$ ), absence of distant metastatic disease (pM0), lymph node ratio smaller than 0.17 , good differentiation grade of the tumor, and $\mathrm{R} 0$ resection were favorable for improved survival.

\section{Discussion}

In this large cohort of patients who underwent esophagectomy for cancer, no differences in overall morbidity, in-hospital mortality, or reoperation rate were detected among the different BMI classes. However, severe complications seemed to occur more often in obese patients than in the control group. Furthermore, a linear association between BMI and anastomotic leakage was detected: the risk for anastomotic leakage increased with higher BMI.
Cancer cachexia has been recognized as a condition associated with an increased risk of postoperative complications [2], in particular infectious complications [3]. However, in the present series it appeared that underweight did not influence the patient's short-term outcome after esophagectomy. When analyzing infectious complications in particular (esp. wound infection and pneumonia), incidences in underweight patients were similar to those in the control group.

Obese patients are thought to have a higher risk for developing wound infections $[6,12,16,17]$. This might be related to the presence of excessive fatty tissue (with a low regional oxygen tension), which may predispose to impaired wound healing. Furthermore, it has been shown that obese patients have an underlying immune impairment, which may further contribute to higher rates of wound infection [18]. Although other reports could not confirm this hypothesis $[11,19,20]$, the risk for wound infection seemed to increase with higher BMI on trend analysis in the present series. Furthermore, we found a linear association between BMI and anastomotic leakage: a higher incidence of anastomotic leakage was found with increasing BMI. In one study in which a significantly increased incidence of anastomotic leakage in obese patients was demonstrated, it was speculated that this might be due to a compromised vascularity of the conduit (because of an increased tension on the conduit in the thoracic compartment or because of medical comorbidities in general, such as diabetes or cardiovascular disease).

In contrast to previous studies, we did not find differences in respiratory complications nor in laryngeal nerve
Fig. 1 Overall 5-year survival in relation to BMI classes in 556 patients who underwent surgical resection for esophageal cancer

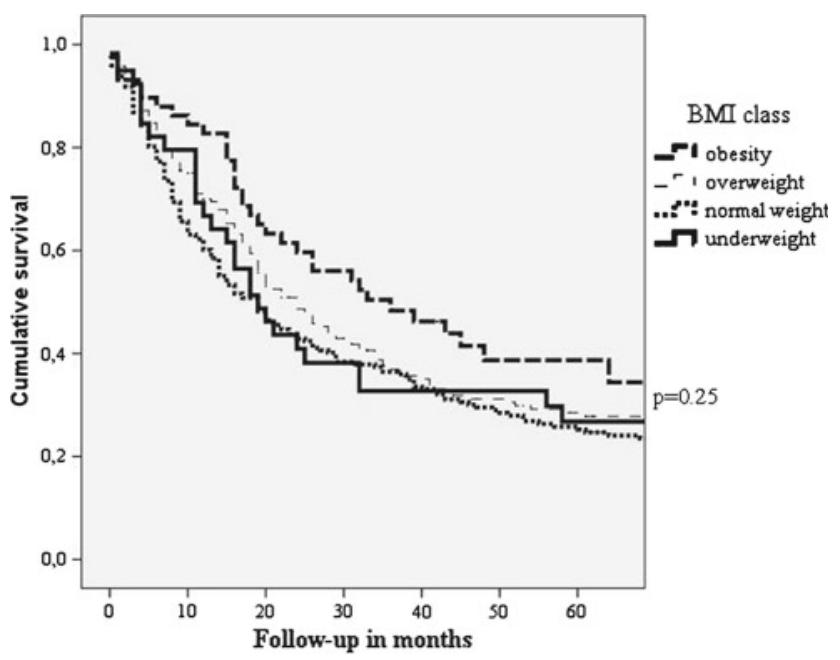

\begin{tabular}{|l|c|c|c|c|c|c|}
\hline No. at risk & 0 months & 12 months & 24 months & 36 months & 48 months & 60 months \\
\hline Underweight & 40 & 26 & 15 & 11 & 11 & 9 \\
\hline Normal weight & 244 & 147 & 97 & 75 & 56 & 46 \\
\hline Overweight & 214 & 138 & 89 & 59 & 47 & 40 \\
\hline Obesity & 58 & 47 & 33 & 23 & 14 & 10 \\
\hline
\end{tabular}


Table 4 Univariate analyses of variables associated with overall survival in esophageal cancer patients who underwent surgical resection

\begin{tabular}{|c|c|c|}
\hline Variable & 5-year survival (\%) & $p$ value \\
\hline \multicolumn{3}{|l|}{ BMI class } \\
\hline Underweight & 26.8 & \multirow[t]{4}{*}{0.25} \\
\hline Normal weight & 25.2 & \\
\hline Overweight & 28.5 & \\
\hline Obesity & 34.4 & \\
\hline \multicolumn{3}{|l|}{ Gender } \\
\hline Male & 26.6 & \multirow[t]{2}{*}{0.5} \\
\hline Female & 33.4 & \\
\hline \multicolumn{3}{|l|}{ Age (year) } \\
\hline$<65$ & 33.7 & \multirow[t]{2}{*}{$<0.001$} \\
\hline$\geq 65$ & 22.3 & \\
\hline \multicolumn{3}{|l|}{ ASA classification } \\
\hline $\mathrm{I} / \mathrm{II}$ & 28.5 & \multirow[t]{2}{*}{0.11} \\
\hline III/IV & 25.9 & \\
\hline \multicolumn{3}{|l|}{ Histology } \\
\hline Squamous cell carcinoma & 26.0 & \multirow[t]{2}{*}{0.53} \\
\hline Adenocarcinoma & 28.3 & \\
\hline \multicolumn{3}{|l|}{ pT stage } \\
\hline pT1-2 & 55.5 & \multirow[t]{2}{*}{$<0.001$} \\
\hline pT3-4 & 14.5 & \\
\hline \multicolumn{3}{|l|}{$\mathrm{pN}$ stage } \\
\hline pNO & 52.7 & \multirow[t]{2}{*}{$<0.001$} \\
\hline pN1 & 12.9 & \\
\hline \multicolumn{3}{|l|}{ pM stage } \\
\hline pM0 & 32.3 & \multirow[t]{2}{*}{$<0.001$} \\
\hline pM1a/M1b & 8.1 & \\
\hline \multicolumn{3}{|l|}{ Lymph node ratio } \\
\hline$<0.17$ & 44.9 & \multirow[t]{2}{*}{$<0.001$} \\
\hline$\geq 0.17$ & 11.5 & \\
\hline \multicolumn{3}{|l|}{ Differentiation grade of tumor } \\
\hline Good & 70.2 & \multirow[t]{3}{*}{$<0.001$} \\
\hline Moderate & 30.3 & \\
\hline Poor & 19.1 & \\
\hline \multicolumn{3}{|l|}{ Radicality of resection } \\
\hline R0 & 37.9 & \multirow[t]{2}{*}{$<0.001$} \\
\hline R1/R2 & 4.8 & \\
\hline
\end{tabular}

BMI body mass index, ASA classification American society of anesthesiologists classification

injury between the BMI classes [11, 20]. This discrepancy with the literature might be explained by a difference in the applied surgical technique. Whereas the majority of our patients underwent a transhiatal esophagectomy, in the previously reported patient group a transthoracic technique was applied [11]. It is known that transthoracic esophagectomy is associated with more pulmonary complications compared with the transhiatal approach [21].
In this study advanced pT stage was seen significantly more often in patients with a low or normal BMI compared with patients with a high BMI $(p=0.02)$. This might be explained by the fact that overweight people experience more reflux symptoms and are offered upper gastrointestinal endoscopy more frequently, thereby facilitating an early detection of the esophageal tumor. Furthermore, in the underweight group patients with a squamous cell carcinoma were overrepresented, who would not have entered a Barrett's esophagus surveillance program. Indeed, patients with overweight or obesity were participating more often in a surveillance program than patients with a low or normal BMI (28.8 vs. $17.1 \%$ ), although this difference did not reach statistical significance $(p=0.21)$. It is well-established that stage of disease and survival are more favorable for patients who have undergone endoscopic surveillance than for patients who have not participated in a surveillance program [22, 23].

We hypothesized that a higher percentage of tumor-free circumferential resection margins might be achieved when performing esophagectomy for cancer in overweight or obese patients because of the presence of more substantial fatty tissue surrounding the tumor. Indeed, on trend analysis, a significant linear association between BMI and R0-resection rate was found $(p=0.02)$ : $60 \%$ in underweight patients versus $81 \%$ in obese patients. However, pT stage acted as a confounder for this relationship, because BMI was not an independent predictor for $\mathrm{R} 0$ resection on logistic regression. Therefore, our hypothesis that a higher percentage of tumor-free circumferential resection margins might be achieved in obese patients because of the presence of more fatty tissue surrounding the tumor could not be confirmed. Furthermore, higher BMI did not result in improved long-term survival after resection and BMI class was not a predictor of survival after esophagectomy in univariate analysis.

Selection bias may be a limitation of this study, because only patients who were considered fit enough for an operation were entered into this study. Therefore, severely malnourished patients or patients with severe obesityassociated medical comorbidities (including diabetes, hypertension, and coronary artery disease) were more likely to have been excluded from surgery. This may have lead to a properly selected patient group, sufficiently fit to undergo esophagectomy, in whom no impact of underweight or obesity on patient's short-term and long-term outcome could be demonstrated.

In summary, BMI is not of prognostic value with regard to short-term complications or long-term survival in patients who undergo esophagectomy for cancer. A radical R0 resection was achieved more often in patients with high BMI. However, this was not due to the presence of more substantial fatty tissue surrounding the tumor (potentially 
facilitating a radical resection). Rather, this observation should be explained by a confounding effect of pT stage, because early pT stage was seen more often in patients with high BMI. We conclude that patients who are oncologically eligible for esophagectomy should not be denied surgery on the basis of their BMI class only.

Acknowledgment The authors are indebted to Mrs. C. M. VollebregtUiterwijk for her dedicated prospective collection of data.

Open Access This article is distributed under the terms of the Creative Commons Attribution Noncommercial License which permits any noncommercial use, distribution, and reproduction in any medium, provided the original author(s) and source are credited.

\section{References}

1. Daly JM, Fry WA, Little AG et al (2000) Esophageal cancer: results of an American college of surgeons patient care evaluation study. J Am Coll Surg 190:562-572 (discussion 572-563)

2. Warnold I, Lundholm K (1984) Clinical significance of preoperative nutritional status in 215 noncancer patients. Ann Surg 199:299-305

3. Heys SD, Schofield AC, Wahle KW, Garcia-Caballero M (2005) Nutrition and the surgical patient: triumphs and challenges. Surgeon 3:139-144

4. Ogden CL, Carroll MD, Curtin LR et al (2006) Prevalence of overweight and obesity in the United States, 1999-2004. JAMA 295:1549-1555

5. Williamson DF (1993) Descriptive epidemiology of body weight and weight change in U.S. adults. Ann Intern Med 119:646-649

6. Dindo D, Muller MK, Weber M, Clavien PA (2003) Obesity in general elective surgery. Lancet 361:2032-2035

7. Renehan AG, Tyson M, Egger M et al (2008) Body-mass index and incidence of cancer: a systematic review and meta-analysis of prospective observational studies. Lancet 371:569-578

8. Enzinger PC, Mayer RJ (2003) Esophageal cancer. N Engl J Med 349:2241-2252

9. Adams JP, Murphy PG (2000) Obesity in anaesthesia and intensive care. Br J Anaesth 85:91-108
10. Flancbaum L, Choban PS (1998) Surgical implications of obesity. Annu Rev Med 49:215-234

11. Healy LA, Ryan AM, Gopinath B et al (2007) Impact of obesity on outcomes in the management of localized adenocarcinoma of the esophagus and esophagogastric junction. J Thorac Cardiovasc Surg 134:1284-1291

12. Mullen JT, Davenport DL, Hutter MM et al (2008) Impact of body mass index on perioperative outcomes in patients undergoing major intra-abdominal cancer surgery. Ann Surg Oncol $15: 2164-2172$

13. van Heijl M, van Lanschot JJ, Koppert LB et al (2008) Neoadjuvant chemoradiation followed by surgery versus surgery alone for patients with adenocarcinoma or squamous cell carcinoma of the esophagus (CROSS). BMC Surg 8:21

14. Sobin L (2002) TNM classification of malignant tumors. Wiley, New York

15. World Health Organization $\mathrm{CoO}$ (2000) Obesity: preventing and managing the global epidemic. Report of a WHO consultation on obesity. World Health Organization, Geneva, Switzerland

16. Roberts JV, Bates T (1992) The use of the body mass index in studies of abdominal wound infection. J Hosp Infect 20:217-220

17. Thomas EJ, Goldman L, Mangione CM et al (1997) Body mass index as a correlate of postoperative complications and resource utilization. Am J Med 102:277-283

18. Tanaka S, Inoue S, Isoda F et al (1993) Impaired immunity in obesity: suppressed but reversible lymphocyte responsiveness. Int J Obes Relat Metab Disord 17:631-636

19. Morgan MA, Lewis WG, Hopper AN et al (2007) Prognostic significance of body mass indices for patients undergoing esophagectomy for cancer. Dis Esophagus 20:29-35

20. Scipione CN, Chang AC, Pickens A et al (2007) Transhiatal esophagectomy in the profoundly obese: implications and experience. Ann Thorac Surg 84:376-382 discussion 383

21. Hulscher JB, van Sandick JW, de Boer AG et al (2002) Extended transthoracic resection compared with limited transhiatal resection for adenocarcinoma of the esophagus. $\mathrm{N}$ Engl $\mathrm{J}$ Med 347:1662-1669

22. Tytgat GN, Van Sandick JW, Lanschot JJ, Obertop H (2003) Role of surveillance in intestinal metaplasia of the esophagus and gastroesophageal junction. World J Surg 27:1021-1025

23. van Sandick JW, van Lanschot JJ, Kuiken BW et al (1998) Impact of endoscopic biopsy surveillance of Barrett's oesophagus on pathological stage and clinical outcome of Barrett's carcinoma. Gut 43:216-222 